\title{
Winds of growth may signal brewing health spending storm
}

Cite as: CMAJ 2017 November 27;189:E1467-8. doi: 10.1503/cmaj.109-5529

Posted on cmajnews.com on Nov. 7, 2017.

rowth in health spending is picking up again after nearly a decade of relative restraint, the Canadian Institute for Health Information (CIHI) reports.

Total health spending in Canada is forecast to grow by $3.9 \%$ to reach $\$ 242$ billion or $\$ 6604$ per person in 2017. That's almost $\$ 200$ more per person than in 2016 , and represents a slight increase in the rate of health spending growth. Since 2010, the average annual increase has been $3.2 \%$.

"We're starting to see the winds of growth pick up a little bit," says Christopher Kuchciak, manager of Health Expenditures at $\mathrm{ClHI}$. "It doesn't mean the storm is here yet but we're seeing the signs."
At the start of the decade, "we were seeing growth rates under 3\%, barely keeping pace with inflation and population growth, and that was a byproduct of governments running deficits and going through a period of fiscal restraint," he says. But in the past few years, growth in health spending has overtaken growth in the economy as Canada has bounced back from global recession.

The last time this happened, the controlled spending of the mid-1990s gave way to growth rates as high as $7 \%$ in the early 2000s, explains Kuchciak. The question remains, "is that sustainable?"

Peers in the Organisation for Economic Cooperation and Development have reported a similar uptick in health spend- ing as economic prospects improve. However, Canada is still one of the highest spenders on health care, and a lower-thanaverage share of those expenses come from the public purse.

Health spending varies across the country, from a high of $\$ 17150$ per person in the Northwest Territories, to a low of \$6321 per person in British Columbia. The Northwest Territories also reported the greatest growth in spending, up 6.8\% from 2016, while Saskatchewan reported the smallest increase at $0.2 \%$. Many factors contribute to these differences; for example, the territories face a greater burden of expensive rural and remote care, while Saskatchewan had to restrain spending in the wake of an oil slump.

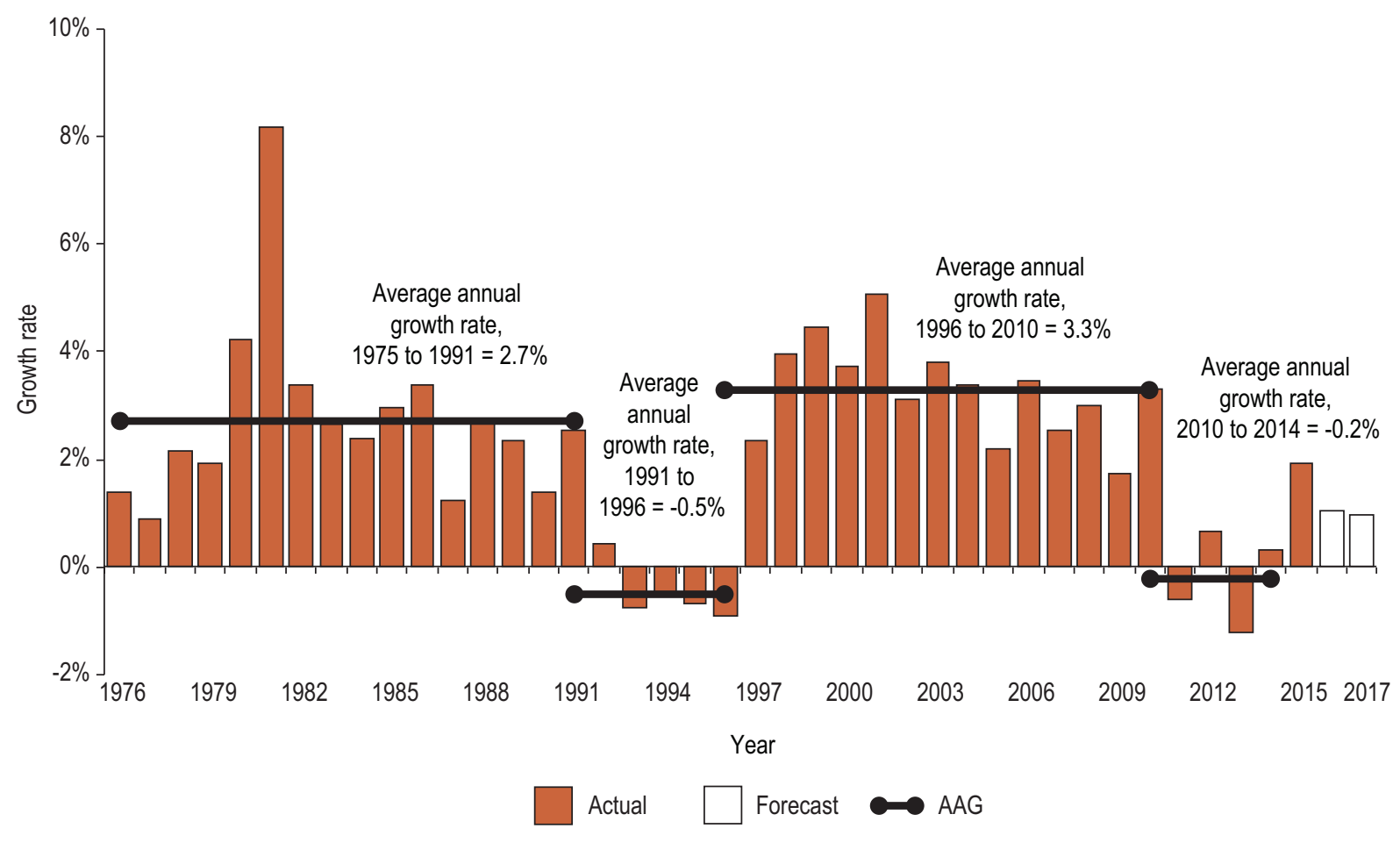

Canada may be poised for an upswing in health spending as economic prospects improve. 
The aging population is also a modest, but steady, cost driver. From 2005 to 2015, the share of health spending on Canadians over age 65 rose from $44.3 \%$ to $46 \%$, while the senior population grew from $13.1 \%$ to $16.1 \%$.

Hospitals, drugs and physician services remain the top expenses, accounting for $28.3 \%, 16.4 \%$ and $15.4 \%$ of health dollars, respectively. Drug spending is growing the fastest of these categories, and is expected to reach $\$ 39.8$ billion or $\$ 1012$ per person in 2017 , up $4.2 \%$.

This rise in drug spending represents a slight uptick from the "very modest rates of growth" of this decade, says Kuchciak. Growth rates less than 4\% were achievable because "you had brand name drugs going off patent and a conscious effort to substi- tute for cheaper generics," he explains. "Now, we have these newer, more expensive drugs such as biologics coming to market, and we're seeing a pick-up again."

Most drug spending comes from private pockets, either from patients or their insurers. However, public drug plans are also feeling strain. Public drug spending increased $9.3 \%$ in 2015 and $4.5 \%$ in 2016, largely driven by the uptake of new hepatitis C drugs, which start at $\$ 45000$ for a full course. The $2 \%$ of Canadians with drug costs over $\$ 10000$ accounted for a third of public drug spending in 2016.

Growth in physician services, as well as the number and compensation of doctors, is also contributing to increasing health expenditures. Physician spending is expected to grow $3.4 \%$ to $\$ 1014$ per person in 2017, and may continue to increase as the population ages and more care is shifted from the hospital to the community.

Although hospitals account for the largest share of total health expenses, the average annual growth in spending has been slowing from 6.4\% between 2003 and 2011, to less than 3\% since 2013. Partly, this has been maintained through "containing the growth in the number of employees or containing their wages," Kuchciak says. Again, this raises questions about the sustainability of the status quo, as greater pressure on hospitals might increase demand for more staff and better compensation. "If they've been getting minimal or zero increases in the last few years, will that continue?"

Lauren Vogel, CMAJ 